\title{
Research on the Business Model of China Mobile Music
}

\author{
Lin Yu and Jiaran Ding \\ College of Music ,Jiangxi University of Technology
}

Keywords: Mobile Music; Industrial Chain; Business Model

\begin{abstract}
The digital music began to spread online from last century 90s. It appears many sites that can audition on the Internet since 20th century, after then digital music gradually spread from the wired network to mobile networks, whose prosperity attracts more and more attention to this field. Digital music has brought new vigor to the gradually depressed music industry, and has brought new hope to the music industry which has been infringed by piracy for a long time. The development of digital music industry, especially the success of mobile music industry, needs us to not only pay attention to the development of the industry but also to accelerate the research on mobile music industry. Taking the development process of mobile music, industry chain and industry environment analysis as the foundation, this paper summarizes the successful business model of the development of mobile music through the case analysis on the successful enterprise in mobile music industry.
\end{abstract}

\section{Introduction}

In the last century 90s, with the rapid development of social productive forces, the human economy becomes increasingly spiritualized. Spiritual factor is playing an increasingly important role in economic activities. The development of world economy entered the era of knowledge economy. In the background of such times, the cultural industry is rising globally.

The development of electronic technology has created the formation and development of the traditional recording industry, nowadays, the development of digital and Internet technology also created the rise of the digital music industry. The development of digital music can be described as by leaps and bounds. It is predicted that by 2012, the share of the digital music will account for $40 \%$ of the entire music market. The development of digital music makes the music industry have a more diverse choice of profit model than ever before. The propagation of digital music is different from the ways of traditional recording, whose biggest difference is to get rid of the entity form of traditional records. And digital music includes two types: online music and mobile music. The transmission mode without the entity has reduced the transmission cost, and at the same time, the spread range has also been changed. The previous entity records are placed in the music shops or cited on the shelves for sales, comparing to the music store and bookstore, the communication ability of the network is much bigger. This way of communication, not only has the potential to form a huge scale, but also has a very attractive earnings potential, that's to say, digital music brings new hope to the music industry.

The mobile music which is mainly based on pop music is developing rapidly in recent years. Because of the broad audience reach of the music art especially the pop music, mobile music industry has become the most promising and profit potential part in the digital content industry, and therefore mobile music has become the focus that everybody pays close attention to in recent years. As a new music industry, mobile music has a revolutionary change compared with the traditional 
music industry. It is not only the important earnings projects of China Mobile, China Unicom and other mobile network operators, but also become the new hope for the Chinese music industry which in a long-term downturn. Of course, we should recognize the plight of the industry development rationally and how to improve the industrial operation ability of mobile music companies, which is very worthy of our research. To promote the healthy development of china mobile music and even digital music industry, we must improve the ability of the enterprise operation to make the enterprise consistently profitable.

The development of mobile music industry needs theoretical system research. At present, the research for the development of mobile music industry is relatively small, most of the research are for the overall study of the digital music industry. In some of the outstanding papers for digital music industry research, although it also involves the research of mobile music, but the content of the research is relatively broad and lack of pertinence. Compared to the vigorous development of China mobile music enterprise, the research on the business model of China mobile music is lagging behind.

Based on the core concept of mobile music, developing process of mobile music industry, industrial chain composition and environment industrial development, this paper researches and summaries the business mode of the success of mobile music business through the case analysis on the successful enterprise in mobile music industry. The huge development potential of mobile music makes it an important part of the cultural industry. Therefore, the theoretical research of mobile music industry not only has practical meaning for the development of the digital music industry, but also has a powerful impetus for the development of the whole cultural industry.

\section{The Concept of Mobile Music}

In the discussion of the concept of mobile music, we cannot divorce from the core concept: digital music. Simply put, digital music refers to the music which created in series of processes of music creation, music editor, music storage and music communication that operated in a digitalized way, and mainly communicated through the wired network and mobile communication network.

Mobile music, also known as mobile music. It refers to the digital music business which being transmitted to mobile communications terminals through the model of mobile value-added service and mobile communications networks. The so-called mobile value-added service is the service that can be chosen by users according to different users and market needs, and which based on the mobile basic service (voice service) by the mobile operators. Value-added services include many aspects, and a variety of services related to life, work, learning, entertainment, management, control and so on are defined as mobile value-added services. Of course, the mobile value-added services discussed in this paper is about mobile music. The service of mobile music mainly includes: mobile phone ringtone download, CRBT download, WR (wireless voice value-added service, which is similar to the currently well-known fixed telephone voice service) music on-demand and the whole song downloads.

\section{The Advantages of Mobile Music}

The Breakthrough of the Music Communication Ways. The biggest difference between the mobile music communication and the traditional music communication is that there is no need of the object of $\mathrm{CD}, \mathrm{LD}$, tape and so on in the process of mobile music's transmission. The digital music, 
including mobile music, has completely changed the way of communication. Mobile music makes it more convenient for the dissemination of music by the mobile communications network which with a very wide range of coverage. On the other hand, by 2010 the number of Chinese mobile phone users has reached 695000000, such a huge number of mobile phone users will be more conducive to the dissemination and promotion of mobile music. Compared with the cable music in the digital music, mobile music can be downloaded and saved into the terminal equipment (mobile phone) in the means of data through mobile communication network, which is more convenient and easy. The breakthrough of the mobile music communication will have a tremendous impetus for the dissemination of the music.

Rapid Communication Speed of Mobile Music. Traditional music is eventually bought by consumers in the form of a CD or tape. Leaving aside how many intermediate links there are a CD from publishing to issue and to the record shops and the bookstores, even for the on-sale records, it is still not an easy thing for consumers to buy in the fastest time due to the relatively limited scope of the record shops and the bookstores. Compared with the music communication of the entity record, digital music is transmitted by the network whose speed has more advantages especially in the days that network technology is increasingly mature. The speed advantages of mobile music in the digital music is more obvious because of the convenience of the transmission mode. The high coverage of mobile communication network and the popularity of terminal equipment (mobile phone) satisfy the consumers' desire to enjoy music anytime and anywhere.

The Production and Dissemination of Mobile Music is Relatively Easy. Traditional music production need music author with professional background and professional music production equipment to realize, during which a lot of time and energy have been spend. At the same time, traditional music is communicated in specialized channels through the logistics system, the communication process of entity is complex and human and financial resources consumed. While the production of mobile music can be carried on by means of many advanced music production software. In no need of professional background, an ordinary music lovers can master the software usage by learning for a certain period of time and make their own personality music. Easily clicking, the created music can spread by putted on the Internet. The process of the music communication becomes very simple.

\section{The Production Enterprise in the Record Industry Chain}

The contents of the recording industry include the artist excavated or the collection of the recording material, the cultivation of the artist and the production of the original record demo. In the process, the main business involves record company and the Broker's Firm. The music industry is an important part of the cultural industry. For the album itself, it just appears as a carrier in the sales process, and it is the music content the album carries that can really stimulate consumers' desire to purchase. So the record company and Broker's Firm are in the core position in the record industry chain.

As the core enterprise of the music industry, record company is mainly responsible for the production and marketing planning work in the industrial chain. The record company in the early will forecast market demand according to the market research data. Based on grasping the market requirements, the record companies will take the image and voice of the artist as material for record production, complete the creation of original demo through a series of editing and processing, and plan the marketing propaganda which in line with the market demand. There, the record company in 
the publicity record is not only to provide a single sound to consumers, but also to be the entertainment elements even for hot news with the image of the artist. The value of the core content of the record is improved by the combination of various aspects. There are many famous record companies in the world, such as Warner, Globe and etc. in recent years there have been some competitive record companies in China, for example: Huayi Brothers Music, Taihe Rye Music and so on.

In the production link of the record contents, the Broker's Firm mainly provides the artist resources for the music content of the record company. The Broker's Firm has actually become a bridge between the record companies and the artists. In terms of the Broker's Firm, the domestic well-known are: Huayi Brothers, Golden Harvest etc. Of course, in order to reduce the cost, there are many strong record companies establish their own Broker's Firms.

Of course, in addition to the record companies and Broker's Firm, the mass production of music also cannot do without music product producer, which is not the focus here. For production enterprise, both record company and Broker's Firm belong to the upstream enterprise in the whole industry chain. The upstream enterprises are particularly important due to the determinative role that the content play in the album sales, and they constitute the core pillar of the whole industry chain.

\section{Industrial Environment (PEST) Analysis of China Mobile Music}

Policy Environment. The development of mobile music industry needs a favorable policy environment to promote the industrial development, and a good policy environment means that the development of mobile music requires a good industrial management mechanism and excellent laws and regulations. They are the most direct factor for the development of mobile music industry.

Economic Environment. The level of social economy determines the quality of people's life, which directly reflects people's needs. Humanistic psychologist Maslow arranges people's demand into certain levels from low to high order, namely physiological needs, safety needs, belongingness and love needs, esteem needs and self-actualization needs, in which self-actualization needs is the most advanced need. Absolutely people will not enter the advanced needs of self-realization before the lower level needs such as the need for food, water, the need for security, stability and he need for love, affection, etc. being fulfilled. The needs of self-actualization include the need of cognition, aesthetics and creativity. People's pursuit of music meets the aesthetic needs of people. The need is based on the premise that the lower-leveled needs have been met. So how to meet the lower-leveled needs, the answer is absolutely based on the economy.

Social Environment. With the development of mobile music, digital music, including mobile music, is gradually accepted by people and becomes the hot spot of consumption. Entertainment consumption occupies a very important position in the mass consumption. And the entertainment consumption which represents by mobile music consumption not only to meet people's daily entertainment psychology, but also become a kind of fashionable consumption habit. The development of mobile networks and the convenient download of mobile music accelerates the formation of this consumer habits. Compared with the traditional record consumption, the download of mobile music is simpler and the carrying of mobile music which takes mobile phone as the carrier is more convenient. At the same time, the consumption of mobile music is much cheaper than traditional record, because the consumers no longer need to buy the whole album just for one piece of work. Paying to download your favorite music from massive mobile music library fully meet the aesthetic needs of consumers. Therefore, the consumption psychology of the consumers is the main 
influence on the development of the mobile music industry in the social environment. Consumption psychology and the development of mobile music industry influence each other. The development of the industry changes the consumption psychology of the consumers, and the changes of consumption psychology promote the development of the industry. This paper is mainly from the convenience of consumption, consumption prices and consumption personality to discuss the consumption psychology. In recent years, the industry policy around mobile music gradually becomes clear and the mobile music industry chain will be more perfect. The development of mobile music, the change of consumption patterns will get more and more attention.

Technical Environment. The change of technology has had a tremendous impact on the music culture. From the birth of the first disc to the formation of the recording industry, or from the black tape record to the $\mathrm{LD}$, tape and to $\mathrm{CD}$, every change cannot be divorced from the technological innovation. The emergence of the Internet and digital music is also the result of technological change. But this changes is different from the ever before, because it completely changed the means of music communication and abandoned the material carrier of music. What more valuable is that mobile music has changed people's traditional consumptive concept of music and brought a new personality consumption to the consumers. Before the advent of digital music especially the mobile music, the consumer is guided by music producer to consume music, the music products that consumers can choose are always limited and even is a kind of passive consumption. Mobile music has completely changed this consumption mode. Consumers can download their favorite music works through the network and the consumption mode is truly changed from passive consumption to active consumption. The emergence of mobile music meets the need of consumers' pursuit for individuality and taste, so it has changed the traditional consumption mode. On the other hand, the change of consumption patterns will accelerate the transformation of the music industry, and music industry practitioners have to change the previous mode of transmission in order to meet the needs of the market and consumers' consumption patterns. Technological innovation promotes the development of mobile music industry.

\section{Business Model of China Mobile Music}

The research and formulation of the business model of mobile music enterprise should involve the following aspects:

A successful business model must firstly be based on meeting the needs of customers, and there is a complementary relationship between meeting the needs of customers and the profitability of the enterprise. The enterprise will profit when the needs of customers are fully fulfilled and the customer value are maximized. The profits that enterprises obtained is the basis to continuous operation for the enterprise. It can achieve the aim of continuously meeting the needs of customers through the operation, and then it provides the possibility for enterprise to continuously profit. In mobile music enterprises, no matter content providers, service providers or mobile operators should take fully satisfying the customers' need as a principle to develop the business model. In the mobile music industry chain, content providers and value-added service providers meet consumer demand through the provision of rich mobile music products. So for mobile operators, to fully meet customer demand is not only providing mobile music products, what's more important is to insist on a service concept, that is to meet the needs of modern consumers through the personalized service experience.

Mobile music enterprise should be actively involved in the integration of industrial chain while carrying on the operation of enterprises. Content providers in the industrial chain can actively 
conduct the industry fusion with service providers on the advantageous basis of owning music copyright. And the content providers can enhance the enterprise the competitive strength in the industry chain, improve the amount of mobile music profit distribution and increase the enterprise profits by improving their own operation abilities in the mobile music production, packaging and promotion propaganda etc.

As for service providers, they should actively fusion with the content providers on the basis of keeping propaganda advantages of enterprise and to obtain more music copyright. Furthermore, they can dock with the mobile operators on this basis to increase enterprise profits.

As the core enterprise of the industry chain, mobile operators should be actively conduct strategic cooperation with content providers and terminal manufacturers, and fuse with value-added service providers of mobile music to gradually complete the shift from traditional telecom operator to integrated information service provider in the industry chain at the time creating a new mobile music business.

The core competitiveness is also a part of the business model, and the formulation of enterprise's business model is launched around the core competitiveness. The core competitiveness of the content providers is their copyrights of music contents, which is the core elements for profits of the whole mobile music industry. So in the mobile music industry, content provider should make efforts to acquire or agent popular songs and classical music projects through various channels, and make it the basis for enterprises profiting in the mobile music industry to constantly improve its position in the whole industry profit distribution.

Service provider's core competitiveness is the outstanding advantages music content packaging, publicity and highlight as a bridge between content providers and operators in the music industry chain. SP should continuously improve their marketing ability during the enterprise operation to shift it into the core competitiveness of enterprises, so as to maintain the competitive advantages in the industry chain.

In terms of setting up core competitiveness, mobile operators should accumulate users through establishing a competitive mobile music platform for the dissemination, and through reflecting music marketing and price advantage in the interior of the platform. The huge number of users will be the core competitiveness of operators, and will win more shares for the operators in the distribution of product profits.

\section{Conclusions}

With the country's prosperity and the improvement of people's living standards, the use of mobile phone will be more popular in the future. As an important entertainment business in the mobile phone business, mobile music will play a more important role in the future, and changes in consumption habits increase the enjoyment of life, all of these build a more solid foundation for the development of mobile music industry. Along with the popularizing of $3 \mathrm{G}$ and the realization of triple network convergence of radio and TV network, telecommunication network and Internet, mobile music industry chain will have a further expansion, which will bring severe challenges and unprecedented opportunities for the mobile music market. The successful application of business model will provide a solid foundation for mobile music enterprises, which can strengthen the ability of sustained profitability of enterprises and promote the development of the industry.

This paper just carries on some study of the development course, industry background, industry chain and business model of mobile music. Many aspects of mobile music are not fully discussed 
due to the current research on mobile music being relatively few, the complete theoretical system have not been formed which cause a lack of reference data and my limited research ability. For example, the aspects of development trend of mobile music in the new technology, the business model of mobile music and the relationship with the value chain of the industry. In the following research, I will continue to pay attention to the field of mobile music.

\section{References}

[1] WANG Jia-ning. On the digital music industry from the perspective of industry value chain [J]. Journal of faith Teachers College (Philosophy and Social Sciences), 2009(1).

[2] LI Ming-ying. Study on the operation of digital music industry in China [M]. Cheng Du: College of Literature and Journalism, Sichuan University, 2007.

[3] LI Li. On the Development of Digital Music in China from the Perspective of Copyright [D]. Bei Jing: School of Economics and Management, Beijing Jiaotong University, 2009.

[4] CHEN Xiao-juan. Research on Mobile Music Marketing Mode in Digital Music Industry [D]. Bei Jing: School of Economics and Management, Beijing Jiaotong University, 2009.

[5] YAN Wen-jian. The Bell Saves Chinese Music [J]. IT Manager World, 2005(6).

[6] DU Zhou. The Record Company Takes the Wireless Music as the Straw Carrier the Telecommunication Operator Self -built Channel the Biggest Winner [J]. IT Time Weekly, 2008(21).

[7] ZHOU Hong-lei. Music Marketing and Case Analysis [M]. Shanghai Music Press, 2004(3).

[8] LI Zhen-yong. Business Model: the Highest Form of Enterprise Competition [M]. Xinhua Press, 2006.

[9] XIA Song-bin. Thinking on the Value Chain of Mobile Music [J]. China New Communications, 2007(24).

[10] ZHEN Zhong, MING Shu-liang, etc. National Melee of Wireless music [J]. Internet Weekly, 2005, 11(4). 